\title{
Reaction time assessment in children with ADHD
}

\author{
Cristiana Bolfer ${ }^{1}$, Erasmo Barbante Casella², \\ Marcus Vinícius Chrysóstomo Baldo³, Amanda Manzini Mota4, \\ Miriam Harumi Tsunemi ${ }^{5}$, Sandra Pasquali Pacheco ${ }^{6}$, Umbertina C. Reed ${ }^{7}$
}

\begin{abstract}
Attention deficit, impulsivity and hyperactivity are the cardinal features of attention deficit hyperactivity disorder (ADHD) but executive function (EF) disorders, as problems with inhibitory control, working memory and reaction time, besides others EFs, may underlie many of the disturbs associated with the disorder. Objective: To examine the reaction time in a computerized test in children with ADHD and normal controls. Method: Twenty-three boys (aged 9 to 12) with ADHD diagnosis according to Diagnostic and Statistical Manual of Mental Disorders, Fourth Edition, 2000 (DSM-IV) criteria clinical, without comorbidities, Intelligence Quotient $(I Q) \geq 89$, never treated with stimulant and fifteen normal controls, age matched were investigated during performance on a voluntary attention psychophysical test. Results: Children with ADHD showed reaction time higher than normal controls. Conclusion: A slower reaction time occurred in our patients with ADHD. This findings may be related to problems with the attentional system, that could not maintain an adequate capacity of perceptual input processes and/or in motor output processes, to respond consistently during continuous or repetitive activity.
\end{abstract}

Key words: ADHD, executive functions, inhibitory reaction, reaction time and working memory.

Avaliação do tempo de reação em crianças portadoras do transtorno do déficit de atenção/hiperatividade (TDẢH)

\section{RESUMO}

Déficit de atenção, impulsividade e hiperatividade são os pontos cardinais do transtorno do déficit de atenção/hiperatividade (TDAH), mas as desordens da função executiva (FE) tais como os problemas no controle inibitório, memória operacional e tempo de reação, dentre outras funções executivas (FEs) podem estar subjacentes a muitos distúrbios associados a esta desordem. Objetivo: Avaliar o tempo de reação em meninos portadores do TDAH. Método: Participaram 23 pacientes do sexo masculino, de idade entre 9 a 12 anos de idade, com diagnóstico de TDAH sem co-morbidades, estabelecido segundo os critérios do Diagnostic and Statistical Manual of Mental Disorders Fourth Edition (DSM-IV), com Quoeficiente Intelectual $(\mathrm{Q} \mid) \geq 89$, que não tivessem sido medicados para o TDAH. Grupo controle, seguindo os mesmos critérios em relação ao sexo, idade, Ql. O teste utilizado foi o teste psicofísico da atenção voluntária (TPAV). Resultados: Os pacientes do TDAH apresentaram maior tempo de reação na execução do teste em relação aos controles. Conclusão: $O$ tempo de reação apresentou-se mais lento em nossos pacientes portadores de TDAH. Estes achados podem estar relacionados aos problemas do sistema atencional; este grupo não pôde manter uma adequada capacidade de percepção de dados processados e/ou, em responder regularmente durante atividades contínuas ou repetitivas. Palavras-chave: TDAH, funções executivas, inibição de resposta, tempo de reação e memória operacional.

\section{Correspondence Cristiana Bolfer \\ Avenida Rio Branco 917 / Zona 05 87015-380 Maringá PR - Brasil \\ E-mail:cristianaaprendizagem@gmail.com}

Received 30 July 2009

Received in final form 26 October 2009

Accepted 6 November 2009
${ }^{1}$ Psychologist by University of Maringá, Maringá PR, Brazil. Neuropsychologist by University of São Paulo Medical School, São Paulo SP, Brazil (FMUSP). Studying for a Master in Neurology, University of São Paulo Medical School, São Paulo SP, Brazil (FMUSP); ${ }^{2}$ Child Neurologist of Israelite Albert Einstein Hospital, São Paulo SP, Brazil. Child Neurologist of Child Institute, Department of Child Neurology, University of São Paulo Medical School, São Paulo SP, Brazil (FMUSP). Doctor Degree in Neurology, University of São Paulo Medical School, São Paulo SP, Brazil (FMUSP); ${ }^{3}$ Full Profesor, Department of Physiology and Biophysics, Institute of Biomedical Sciences, University of São Paulo SP, Brazil (USP); ${ }^{4}$ Master in Physiology, Institute of Biomedical Sciences, University of São Paulo SP, Brazil (USP); ${ }^{5}$ Doctor Degree in Statistics, Institute of mathematics and statistics, University of São Paulo SP, Brazil (USP); ${ }^{6}$ Psychologist by Pontifical Catholic University, São Paulo SP (PUC). Neuropsychologist by University of São Paulo Medical School, São Paulo SP, Brazil (FMUSP); ${ }^{7}$ Full Professor, Division of Child Neurology, FMUSP. Department of Neurology, University of São Paulo Medical School, São Paulo SP, Brazil (FMUSP). 
Attention deficit hyperactivity disorder (ADHD) is characterized by the combination of attention deficit, hyperactivity and impulsiveness, and is the most commonly diagnosed behavioural disorder of childhood ${ }^{1}$. An estimated $3 \%$ to $6 \%$ of our children and adolescents present such disorder, which interferes in their family, school and social environments, as well as in their school achievement and emotional and affective development ${ }^{2}$. The ADHD diagnosis is fundamentally clinic, based on clear and well defined operational criteria, deriving from classificatory systems such as Diagnostic and Statistical Manual of Mental Health Disorder, Fourth Edition, 2000 (DSM-IV) ${ }^{3}$.

ADHD can be considered a neurobiological disease with alterations in some brain areas and associated circuits. The main affected brain regions are the prefrontal and parietal cortex, the cerebellum, basal ganglia and the associated circuits, which imply in an alteration of the inhibitory control, working memory, reaction time, besides others executive functions ${ }^{4-8}$.

Reaction time is the period between the emerging of the target stimulus and the subject's motor response, i.e., it is the behavioural measurement that the subject can demonstrate their capacity to process the information ${ }^{9}$. In this type of evaluation, only the correct answers are considered.

The aim of this study is assess the reaction time in children with ADHD and normal -controls through a visual voluntary attention psychophysical test (VVAPT), especially focusing on the reaction time measures. This experiment was performed to assess the voluntary attention using the reaction time assessment through a computerized test.

\section{METHOD}

The participants were boys with ADHD combined type, ages 9 to 12, without comorbities, clinical diagnosis according to DSM-IV criteria, IQ $\geq 89$, never treated with methylphenidate and who were followed-up in the outpatient clinic for ADHD at the Central Institute's Infant Neurology Service and at the Children's Institute of the Hospital das Clínicas da Faculdade de Medicina da Universidade de São Paulo (HCFMUSP). The control group followed the same criteria for gender, age and IQ. This research was approved by the Ethical Committee and by the Board of the Neurology Department and the Division of Psychology of the Central Institute of HCFMUSP and all the caregivers signed the informed consent.

This task was done using the "Micro experimental Laboratory- Mel” (Mel professional v 2.01- Psychology Software Tools, Inc). This software modifies the imput and output systems of the computer, allowing register of reaction time in milliseconds. The tests were administered in a PC (IBM compatible) with a 15" screen. A joystick was used as interface between patient and com- puter screen. The battery administration lasted an average of 30 minutes. Initially, the participant was instructed to pay attention to an informative cue that was a cross (fixation point) (Fig 1). It was presented on the center of the computer screen and each participant should stare at throughout the test. After an interval of $700 \mathrm{~ms}$ an arrow / pointer is presented which indicates, with a validity of $70 \%$, the appearance of the target (square) to the correct side (the test is constituted of three blocks, which the arrow pointed to the right, left, fixed and alternated respectively). After an interval of $800 \mathrm{~ms}$, a square is presented for $17 \mathrm{~ms}$ and, when noticing it, the participant must respond by pressing the frontal button of a joystick with the index finger of their dominant hand, as quick as possible. There are two different situations for the appearance of the target. In the first situation, the arrow/pointer and the
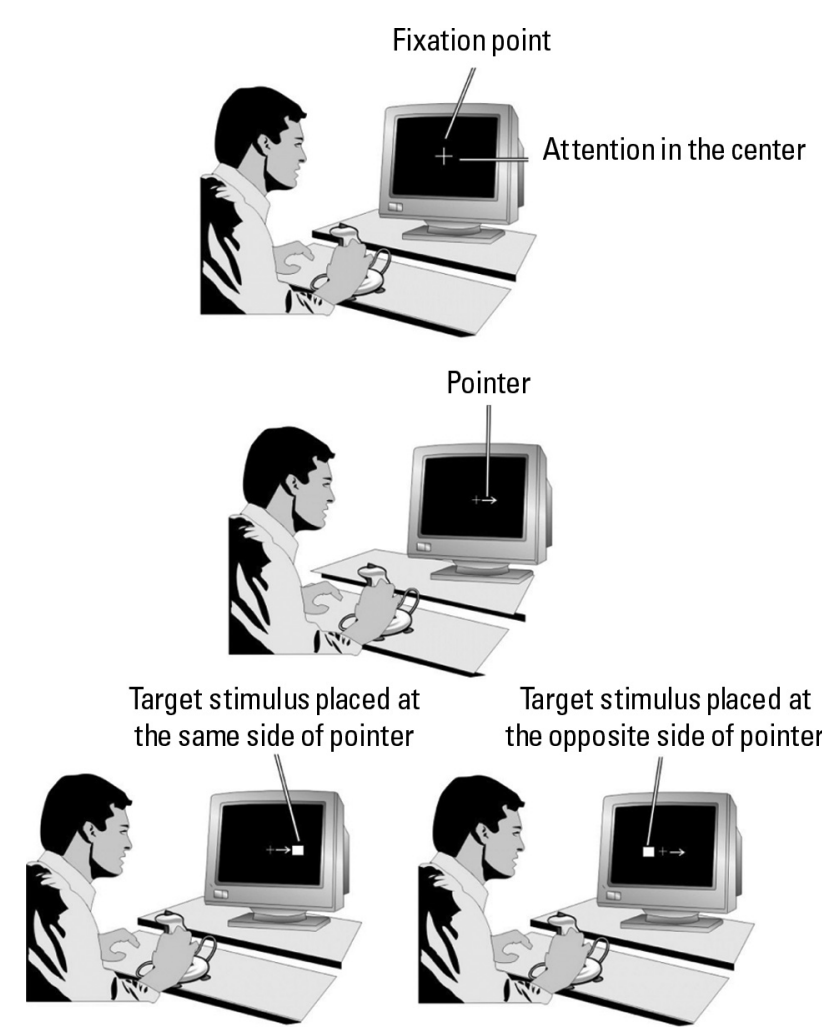

Fig 1. Initially a cross (fixation point) is presented on the screen and each participant should stare at it throughout the test. After an interval of $700 \mathrm{~ms}$ an arrow / pointer is presented which indicates, with a validity of $70 \%$, the appearance of the target (square) to the correct side (*the test is constituted of three blocks: right, left, fixed and alternated respectively). After an interval of $800 \mathrm{~ms}$, a square is presented for $17 \mathrm{~ms}$ and, when noticing it, the participant must respond by pressing the frontal button of a joystick with the index finger of their dominant hand. There are two different situations for the appearance of the target. In the first situation, the arrow/pointer and the square appear on the same direction (Valid Condition) and in the second situation the arrow/pointer and the square appear on opposite sides (Invalid Condition). 


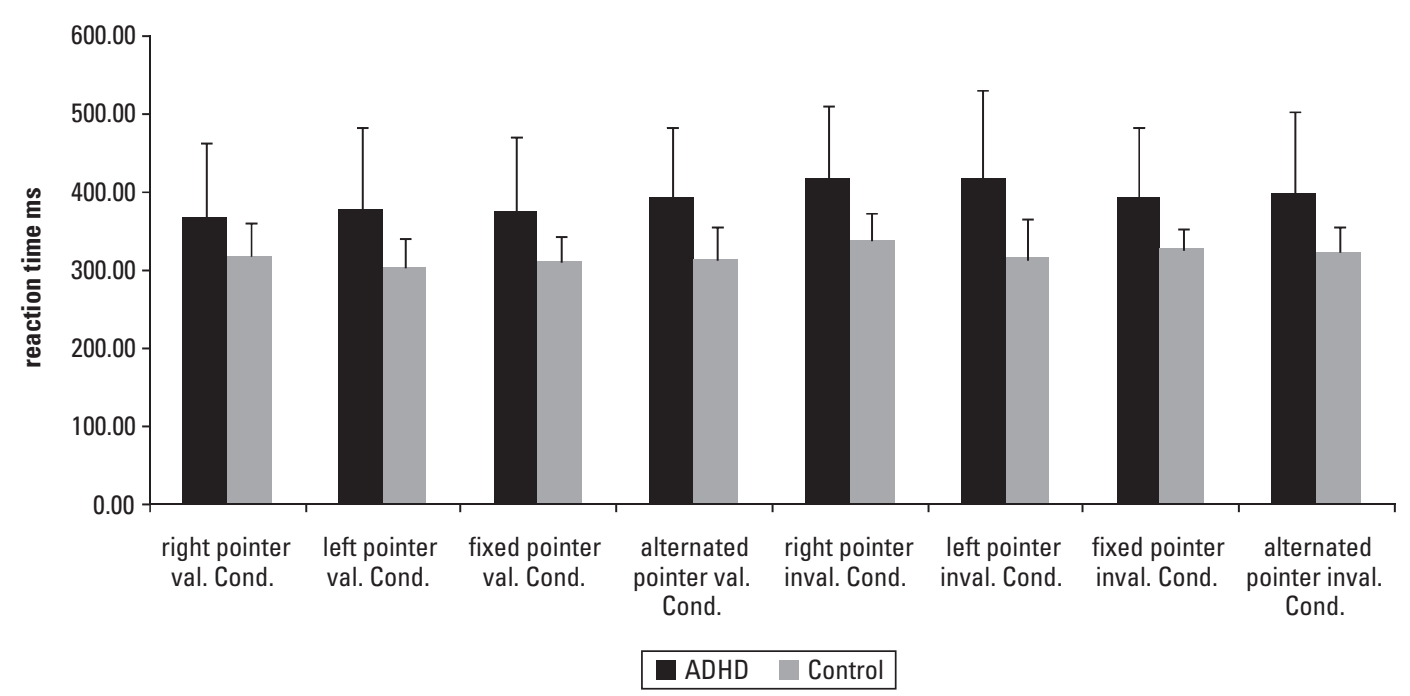

Fig 2. WAPT's means.

Table. Results and mean values for reaction time of performance on visual voluntary attention psychophysical test (VVAPT).

\begin{tabular}{|c|c|c|c|c|c|}
\hline & & $\begin{array}{c}\text { Right pointer } \\
\text { valid condition }\end{array}$ & $\begin{array}{l}\text { Left pointer valid } \\
\text { condition }\end{array}$ & $\begin{array}{c}\text { Fixed pointer } \\
\text { valid condition }\end{array}$ & $\begin{array}{c}\text { Alternated pointer } \\
\text { valid condition }\end{array}$ \\
\hline ADHD & $\begin{array}{l}\text { Mean } \\
\text { SD }\end{array}$ & $\begin{array}{c}368.67 \\
93.85\end{array}$ & $\begin{array}{l}377.50 \\
104.25\end{array}$ & $\begin{array}{c}375.04 \\
96.28\end{array}$ & $\begin{array}{l}392.85 \\
89.15\end{array}$ \\
\hline Control & $\begin{array}{l}\text { Mean } \\
\text { SD }\end{array}$ & $\begin{array}{c}317.35 \\
42.77\end{array}$ & $\begin{array}{c}303.67 \\
37.37\end{array}$ & $\begin{array}{l}310.53 \\
33.40\end{array}$ & $\begin{array}{c}311.68 \\
43.48\end{array}$ \\
\hline Mann-Whitney & & -1.63 & -2.40 & -2.27 & -3.03 \\
\hline \multirow[t]{2}{*}{$p$} & & 0.107 & 0.016 & 0.022 & 0.002 \\
\hline & & $\begin{array}{l}\text { Right pointer } \\
\text { invalid condition }\end{array}$ & $\begin{array}{l}\text { Left pointer invalid } \\
\text { condition }\end{array}$ & $\begin{array}{c}\text { Fixed pointer } \\
\text { invalid condition }\end{array}$ & $\begin{array}{l}\text { Alternated pointer } \\
\text { invalid condition }\end{array}$ \\
\hline ADHD & $\begin{array}{l}\text { Mean } \\
\text { SD }\end{array}$ & $\begin{array}{c}417.03 \\
92.60\end{array}$ & $\begin{array}{l}417.26 \\
114.21\end{array}$ & $\begin{array}{l}392.85 \\
89.15\end{array}$ & $\begin{array}{l}397.38 \\
106.55\end{array}$ \\
\hline Control & $\begin{array}{l}\text { Mean } \\
\text { SD }\end{array}$ & $\begin{array}{c}338.57 \\
33.52\end{array}$ & $\begin{array}{c}313.97 \\
50.23\end{array}$ & $\begin{array}{c}326.41 \\
25.98\end{array}$ & $\begin{array}{c}323.32 \\
31.35\end{array}$ \\
\hline Mann-Whitney & & -2.64 & -2.60 & -2.58 & -2.20 \\
\hline$p$ & & 0.007 & 0.008 & 0.009 & 0.028 \\
\hline
\end{tabular}

SD: standard deviation; p: probability.

square appear on the same direction (valid condition and probability of 70\%) and in the second situation the arrow /pointer and the square appear on opposite sides (invalid condition and probability of $30 \%$. Before this procedure, it was done a training session with the joystick to guarantee the reliability of the results, because it minimizes the possibility of low performances due to low familiarity with the tools.

To ensure that each response represented a true response to the stimulus, only accurate responses occurring between $150 \mathrm{msec}$ and $1000 \mathrm{msec}$ after target onset were analyzed. We hypothesized that an invalid cue would cause a larger increase in RT in the ADHD patients compared to the control groups which would not differ from each other.

The Mann-Whitney, a non parametric-test for relat- ed samples was used in the analysis of the results. The adopted level of significance was $5 \%$.

\section{RESULTS}

The children with ADHD showed reaction time significantly higher than normal controls in VAPT. The results and mean values for reaction time of performance on this test are showed in Table. When the arrow/pointer appeared on the opposite side (invalid condition) the results were worst for the both groups (Fig 2).There were not difference between the groups in the reaction time when the arrow/pointer to the right, as a valid condition.

\section{DISCUSSION}

We used the VVAPT experiment with the aim to study the reaction time. Psychophysical is a quantitative 
branch of the study of the perception, which evaluate the relations between observed stimuli and response and a form of measurement used in most psychophysical studies is through the reaction time ${ }^{9,10}$. In this task, the individual has to compare the order of presentation of two stimuli presented in the visual field at different intervals.

The time of reaction to the achievement of correct answers was higher in our patients with ADHD than the control group in almost all types of evaluations surveyed. It is important to remember that the overall processing speed represents the average speed of correct responses for the entire test, and an averaged slow response time of responding would suggest the person was not paying close attention to the task. Another observation that occurred in ADHD group was a speed decrement over time, suggesting a graduated loss of sustained attention.

We emphasize that as we studied in this test only the accurate responses, the reaction time higher than normal in the ADHD group did not can explained by a inhibition deficit as Barkley hypothesis ${ }^{11}$. Indeed this type of test includes the analysis of the information processing, storage mechanism, selection, support and delivery of the response ${ }^{12}$.

According to Stuss et al. ${ }^{13,14}$ a model of the "cognitive architecture of attention" may be used to explain what occur during procedures like this. He suggested an existence of three separable attentional components in anterior cerebral regions. One attentional system maintains a general state of readiness to respond. This activation state was associated with the superior medial frontal region, and in their study, lesions in this region affected simple RT speed. A second system sets a criterion level of response, or threshold, to a target or external stimulus and establishes a bias for responsiveness. This system was associated with the left dorsolateral frontal region, and lesions in this region altered response bias. A third system maintains the selection of the defined schema to allow for consistent target selection. This system of sustained attention was associated with right dorsolateral frontal regions, and lesions in this region decreased sensitivity in differentiating targets from non targets.

We believe that during the evaluation of time of reaction by the VVAPT we are examining, besides the functioning of the anterior attentional system, also the posterior attentional system. The anterior system act in inhibitory control, cognitive flexibility operational memory, planning, and through connections with subcortical structures, particularly the striatum, controlling the motor response. Furthermore, the posterior system, including the parietal cortex, mesencephalic and thalamic structures, control the automatic perceptual processes ${ }^{15,16}$. During the procedure of voluntary attention is important the integration of all these structures.
The cognitive-energetic model of Sergeant ${ }^{17}$, stresses the importance of the "arousal" and "activation" systems, which control the stimulus perception and production of response, respectively. According to this author, these two processes are maintained and modulated by a third process, "effort" system, which is defined as the energy required to perform the demands and would be related to motivation of the individual. The "arousal" system was associated with the processing of the stimulus and would be highly influenced by the intensity and novelty of it. The "activation" system would be more related to readiness to respond and is strongly influenced by task variables such as preparation, alertness, time of day and time on task.

According some authors deficits in the readiness, organization and monitoring of the responses were more evident in children with combined subtype of ADHD, while losses in the ability of detection and orientation to the stimuli were related to children with predominantly inattentive $\mathrm{ADHD}^{18,19}$. In our opinion, the patients with ADHD combined presents difficulties with the two systems, "arousal" and "activation" and this can be understood by the difficulty in separating the subtypes of ADHD predominantly inattentive and combined, what was also observed by others authors ${ }^{20-22}$.

In conclusion, despite the small number of patients included in the current trial, the performance in this task of ADHD group, that had a slower reaction time, suggest that the VVAPT may be another possible test to be used in the evaluation of these patients. We understand that although the ADHD diagnostic is clinical, this type of instrument may be used at some times, to analyze attention and also the executive functions of the patients with ADHD, as it involves a series of simultaneous controls for proper response. Maybe it will be a good instrument to show in an objective way the effects of treatment in these patients.

\section{REFERENCES}

1. American Academy of Pediatrics. Clinical practice guideline: diagnosis and evaluation of the child with attention-deficit/hyperactivity disorder. Pediatrics 2000;105:1158-1170.

2. Polanczyk G, Lima MS, Horta BL, Biederman J, Rohde LA. The worldwide prevalence of ADHD: a systematic review and metaregression analysis. Am J Psychiatry 2007;164:942-948.

3. American Psychiatric Association Diagnostic and statistical manual of mental disorders. $4^{\text {th }}$ Ed. Washington, DC: American Psychiatric Association, 1994:78-85.

4. Valera EM, Faraone SV, Nurray KE, Seidman L. Meta-analysis of structural imaging findings in attention-deficit/hyperactivity. Biol Psychiatry 2006;15:13611369.

5. Makris N, Bierdeman J, Valera EM, et al. Cortical thinning of the attention and executive function networks in adults with attention-deficit/hyperactivity disorder. Cereb Cortex 2007;17:1364-1375.

6. Bush G, Valera EM, Seidman L. Functional neuroimaging of attention-deficit/ hyperactivity disorder: a review and suggested future directions. Biol Psychiatry 2005; 57:1273-1284.

7. Seidman LJ, Valera EM, Makris N, et al. Dorsolateral prefrontal and anterior cingulate cortex volumetric abnormalities in adults with attention-deficit/ 
hyperactivity disorder identified by magnetic resonance imaging. Biol Psychiatry 2006;15:1071-1080.

8. Shaw P, Eckstrand K, Sharp W, et al. Attention-deficit/hyperactivity disorder is characterized by a delay in cortical maturation. PNAS 2007;104: 19649-19654.

9. Baldo MVC, Haddad HJr, Carreiro LR. The modulation of simple reaction time by the spatial probability of a visual stimulus. Braz J Med Biol Res 2003;36:907-911.

10. Pierce CA, Jewell G, Mennemeier M.Are psychophysical functions derived from line bisection reliable?J Int Neuropsychol Soc 2003;9:72-78.

11. Barkley RA. Attention-deficit/hyperactivity disorder, self-regulation, and time: toward a more comprehensive theory. J Dev Behav Pediatr 1997;18:271-279.

12. Haddad HJR. Estudo de mecanismos atencionais e pré-atencionais envolvidos na percepção visual de ordem temporal. Dissertação, Instituto de Ciências Biomédicas, Universidade de São Paulo. São Paulo, 2003.

13. Stuss DT, Stethem LL, HugenHoltz H, Picton TW, Pivik J, Richard MT. Reaction time after head injury: fadigue, divided and focused attention and consistency of performance. J Neurol Neurosug Psychiatry 1989;79:81-90.

14. Stuss DT, Binns MA, Murphy KJ, Alexander MP.Dissociations within the anterior attentional system: effects of task complexity and irrelevant information on reaction time speed and accuracy.Neuropsychology 2002; 16:500-513.

15. Arnsten AF. Dopaminergic and noradrenergic influences on cognitive functions mediated by prefrontalcortex. In: Solanto MV, Arnsten AF, Castellanos
FX (Eds). Stimulant drugs and ADHD: basic and clinical neuroscience. New York: Oxford, 2001:185-208.

16. Posner M, Petersen SE. The attention system of the brain. Ann Rev Neurosci 1990;13:35-42.

17. Sergeant JA. Modeling attention-deficit/hyperactivity disorder: a critical appraisal of the cognitive-energetic. Biol Psychiatry 2005;57:1248-1255.

18. Klorman R, Hazel-Fernandez LA, Shaywitz SE, et al. Executive functioning deficits in attention-deficit/hyperactivity disorder are independent of oppositional defiant or reading disorder. Am Acad Child Adolesc Psychiatry 1999; 38:1148-1155.

19. Nigg JT, Blaskey LG, Huang-Pollock CL, Rappley MD. Neuropsychological executive functions and DSM-IV ADHD subtypes.J Am Acad Child Adolesc Psychiatry 2002;41:59-66.

20. Geurts HM, Verté S, Oosterlaan J, Roeyers H, Sergeant JA. ADHD subtypes: do they differ in their executive functioning profile? Arch Clin Neuropsychol 2005;20:457-477.

21. Solanto MV, Gilbert SN, Raj A, et al. Neurocognitive functioning in AD/HD, predominantly inattentive and combined subtypes. J Abnorm Child Psychol 2007;35:729-744.

22. Riccio CA, Homack S, Jarratt KP, Wolfe ME. Differences in academic and executive function domains among children with ADHD predominantly inattentive and combined types. Arch Clin Neuropsychol 2006;21:657-667. 